\title{
Why illness might leave a bitter taste in the mouth
}

\section{Molecule that triggers inflammation also seems to influence how mice sense bitter flavours.}

\section{Nala Rogers}

29 April 2015

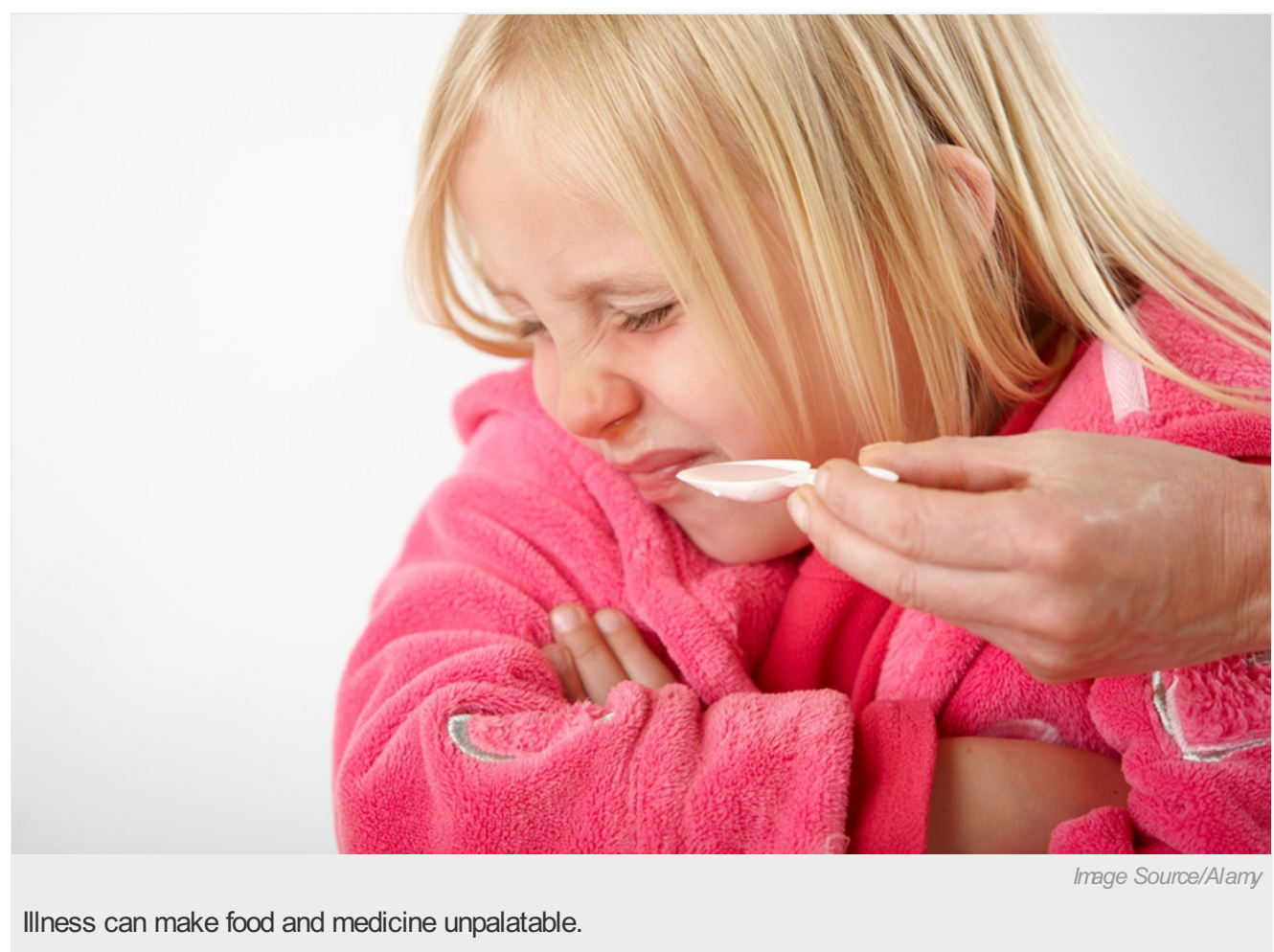

People who are ill often complain of changes in their sense of taste. Now, researchers report that this sensory shift may be caused by a protein that triggers inflammation.

Mice that cannot produce the protein, called tumour necrosis factor- $\alpha$ (TNF- $\alpha$ ), are less sensitive to bitter flavours than normal mice, according to a study published on 21 April in Brain, Behavior, and Immunity ${ }^{1}$.

People with infections, autoimmune disease or other inflammatory conditions have higher levels of TNF- $\alpha$ than healthy people, and the protein has been shown to reduce food intake ${ }^{2}$. To investigate the influence of TNF- $\alpha$ on taste, researchers at the Monell Chemical Senses Center in Philadelphia, Pennsylvania, used engineered mice that could not produce the protein.

The researchers offered the engineered mice and normal mice water that contained different types and concentrations of flavours. The mice that could not produce TNF- $\alpha$ had normal reactions to sweet, sour, salty and umami flavours, but were less sensitive to bitter ones.

"Normal mice will pick up [that taste] at a much lower concentration. They will know this is bitter; they will not like it," says Hong Wang, a molecular biologist at Monell and an author of the study. "But if the TNF- $\alpha$ gene is not there, then the mice will only start to avoid the bitter solution at higher concentrations."

\section{Taste sensation}

In some of the experiments, the mice could drink their fill of either plain water or a flavoured solution; researchers measured the changing levels in water bottles to determine how sensitive the mice were to a particular taste. In other experiments, the mice had only a few seconds to drink while a machine counted how many times they licked the flavoured solution - a test that minimizes the influence of any after-effects that the mice feel on drinking the test liquids. 
liquids on the basis of taste and not because of any after-effects of the flavour.

But the behaviour experiments could not determine whether the reduced reactions to bitterness reflected changes in the mouse tongue or in the parts of the brain that process taste. To find out, the researchers recorded electrical activity in the nerves that transmit taste signals from the tongue to the brain. In the engineered mice, these peripheral taste nerves fired less in response to bitter flavours than they did in normal mice, suggesting that TNF- $\alpha$ acts on the taste buds themselves.

That is a relatively new idea, says Jan-Sebastian Grigoleit, a neuroimmunologist at the Salk Institute for Biological Studies in La Jolla, California. TNF- $\alpha$ falls into a class of small signalling molecules called cytokines that are best known for their roles in the immune response. But Grigoleit says that researchers have been discovering that cytokines also help to regulate other body systems.

\section{Tongue-tied}

Robert Dantzer, a psychobiologist at the University of Texas MD Anderson Cancer Center in Houston, cautions that the new study's findings could have multiple explanations. For example, growing up without TNF-a may have caused developmental abnormalities in the engineered mice that could explain their tolerance for bitter flavours.

Meanwhile, the study's authors are surprised that a lack of TNF- $\alpha$ affected only perception of bitter tastes, because they found that many types of taste cells seem to have receptors for the protein. (Some cells in the tongue's taste buds also produce the protein, but these cells specialize in sensing sweet and umami flavours ${ }^{3}$.)

Wang says that the team now plans to investigate whether high TNF- $\alpha$ levels during illness make people extra-sensitive to bitter tastes.

Nature | doi:10.1038/nature.2015.17415

\section{References}

1. Feng, P. et al. Brain Behav. Immun. http://dx.doi.org/10.1016/j.bbi.2015.04.001 (2015).

2. Langhans, W. \& Hrupka, B. Neuropeptides 33, 415-424 (1999).

3. Feng, P., Zhao, H., Chai, J., Huang, L. \& Wang, H. PLoS ONE 7, e43140 (2012). 